\title{
A RELAÇÃO ENTRE ELINÁ E DONA LAIR EM “OS OBJETOS”, DE DINORATH DO VALLE
} THE RELATIONSHIP BETWEEN ELINÁ AND DONA LAIR IN “OS OBJETOS", BY DINORATH DO VALLE

\author{
Pâmela Coca dos Santos Ramos ${ }^{1}$
}

\begin{abstract}
Resumo: Este artigo analisa a relação entre as personagens principais do conto "Os objetos", um dos finalistas do Concurso de Contos Eróticos da Revista Status, em 1977, e publicado na coletânea de contos Idade da Cobra Lascada, de Dinorath do Valle, em 1982. Este conto narra o conflito que se estabelece quando Eliná, pobre e assediada pelo pai em sua casa, recebe oferta de moradia de sua professora, Dona Lair, que também a assedia quando a menina, de 13 anos, visita sua casa.
\end{abstract}

Palavras-chave: Dinorath do Vale; Idade da Cobra Lascada; Os objetos.

\begin{abstract}
This essay analyses the relationship between the main characters of the short-story in "Os objetos", one of the finalist of the Concurso de Contos Eróticos of the magazine Status, in 1977, and published on the book Idade da Cobra Lascada by Dinorath do Valle, in 1982; This short-story tells the conflict stablished when Elina, poor and harassed by her father, is offered housing by her teacher, Dona Lair, who also harasses her when the girls, who is 13 years old, visits her.
\end{abstract}

Keywords: Dinorath do Vale; Idade da Cobra Lascada; Os objetos.

Nascida em Itápolis em 1926, Dinorath do Valle, ainda na infância, mudou-se com sua família para São José do Rio Preto, cidade onde viveu o restante de sua vida e onde faleceu em 2004. Além de escritora, Dinorath do Valle foi, também, cronista de rádio, roteirista de cinema, jornalista, historiadora, professora, e uma das fundadoras da Casa de Cultura de São José do Rio Preto, que, em sua homenagem, leva seu nome.

Sua obra literária abarcou não apenas contos, mas, também, romances, crônicas, novelas, livros infantis e roteiros de cinema. Dentre suas publicações, algumas foram premiadas, como, por exemplo, o livro de contos $O$ vestido amarelo, que recebeu o prêmio Governador do Estado (1971). Outras de suas publicações premiadas são: Pau Brasil (romance de 1985, que recebeu o Prêmio Casa de Las Américas em 1982) e Heteros, A comédia (roteiro de 1973, que recebeu os Prêmios de Melhor

1 Mestranda pelo programa de Pós-Graduação em Letras da UNESP, campus de São José do Rio Preto. Desenvolve a pesquisa “As personagens femininas no conto de Dinorath do Valle" com apoio CAPES.

Revista Crioula - n 24 - Dissidências de Gênero e Sexualidade nas Literaturas de Língua Portuguesa 
filme curto no Festival de Chicago e Prêmio Especial do Júri no Festival de Toronto).

Embora tenha sido premiada e tenha tido reconhecimento nos círculos literários, a obra de Dinorath do Valle é, ainda hoje, pouco conhecida e, sobretudo, pouco lida criticamente. O livro de contos $O$ vestido amarelo é um exemplo disso: embora tenha sido escrito por volta de 1971 - quando ganhou o prêmio Governador do Estado - foi publicado apenas em 1976 com seu título modificado, conforme relata Manoel dos Santos Silva, em sua obra Os bárbaros submetidos:

O vestido amarelo é de 1971, mas só em 1976 foi editado pela Artenova, graças ao empenho de Odylo Costa Filho, o apresentador do livro da autora. Seu título anterior, Gurufim, mais sugestivo e adequado à atmosfera dominante na maior parte dos contos, foi substituído por este que lembra exposição de roupas em vitrine de loja e que, por isso mesmo, deve ter parecido, aos editores, mais persuasivo em termos de venda. (SILVA, 2006, p. 136).

A pouca difusão e a escassa leitura crítica da obra de Dinorath do Valle perduram até hoje, e um exemplo disso é o segundo livro de contos da autora, denominado Idade da Cobra Lascada, publicado pela Prelo Editora. Vera Lúcia Guimarães Rezende destaca, em sua tese de doutorado $D a$ crônica Jornalística ao conto: a transformação da escrita em Dinorath do Valle, o conto "Objetos" pelo prêmio recebido:

Trata-se do terceiro livro publicado por Dinorath do Valle, agora pela Prelo Editora, em 1982. Doze contos inéditos emoldurados pelas ilustrações do artista primitivista rio-pretense Daniel Firmino da Silva. Entre eles inclui-se "Os Objetos", premiado no $1^{\circ}$ Concurso Nacional de Contos Eróticos promovido pela revista Status em 1977. (GUIMARÃES, 2019, p. 53).

A revista Status, lançada em 1974, era conhecida por ser uma revista pornográfica masculina e que contava, desde seu primeiro número, com uma seção para publicações literárias: "Na revista Status, desde o primeiro número, havia uma seção denominada 'Ficção' em que se publicava uma novela ou um conto" (REIMÃO, 2008, p. 4). Em 1976, de acordo com Reimão (2008), após publicar textos de escritores renomados tais como Graciliano Ramos, Ignácio de Loyola e Ivan Ângelo, a revista anunciou um concurso literário de contos eróticos cujo resultado foram edições especiais para a publicação dos contos, dentre elas, a coletânea 60 Contos Eróticos, que publicou os contos dos finalistas dos $1^{\circ}$ e $2^{\circ}$ concursos de contos.

A presença do conto "Objetos" nessa revista de contos eróticos se deve à relação construída entre a protagonista e sua professora. De acordo com Rezende, "o erotismo é sugerido quando Eliná 
percebe a ambiguidade do toque da professora" (REZENDE, 2019, p. 53). O conto, no entanto, revela que esse erotismo que prevalece na relação entre as duas tem origem no assédio ${ }^{2}$ que Eliná sofre não só da professora, como, também de seu pai.

O contato entre as duas personagens tem origem na escola e, a princípio, respeita os limites da relação professor/aluno. No entanto, essa relação começa a mudar de curso quando a professora D. Lair pede à Elina que ela a acompanhe até sua casa para ajudá-la a levar os materiais escolares:

Ele saiu da frente do quadro-negro que era verde, pensava sempre nisso, quadro verde. E não falavam quadro-preto, sempre quadro-negro. A lição também, olha o céu como está negro! Não dá para falar assim. Ela saiu da frente dos quatro problemas, três espaços (um de menos). E se voltou para Eliná que pensava, fazia e errava a conta, três vezes sete vinte e um, vai um.

— Você leva os cadernos hoje.

Gostoso ser mandada mas não lá em casa. Gostoso fazer o que todos querem fazer e é só um que faz. (VALLE, 1982, p. 17).

Pode-se perceber, neste trecho, que o pedido e aceitação de ambas as personagens não são gratuitas e antecipam o comportamento "ambíguo" citado por Rezende: D. Lair pede ajuda de maneira premeditada e Eliná gosta de ser escolhida pela professora e de estar submissa a sua autoridade, por isso estabelece o contraste entre obedecer às ordens em casa e obedecer a professora. Outro dado importante presente neste trecho é o narrador de $3^{\text {a }}$ pessoa onisciente neutro que narra as ações e que sofre interrupções do pensamento de Eliná por meio do discurso indireto livre.

É por meio do discurso indireto livre que o conto revela os assédios que Eliná sofre do pai: “Eu sei o que é. Ninguém me ensinou, percebo. Essas bobas não sabem. Eu sei. O Jovelino sabe. O Pai sabe. Ele passa a mão na gente" (VALLE, p. 18). Além do assédio, este trecho também revela ao leitor o dado de que Eliná é uma menina que tem algum tipo de conhecimento sexual. Este conhecimento sexual faz com que ela se sexualize e perceba os atributos físicos como qualidades e como diferencial entre as outras meninas da escola, construindo uma relação de rivalidade com elas:

Já uso sutiā, arredondada. As outras não, totalmente lisas, sem nada em lugar nenhum, só saias e blusas e meias grudadas nas pernas finas. Alice gorducha. E a raiva pelos cadernos que queriam carregar, deixa boba, ela é empregadinha! [...] Alice é a queridinha da Dona Lair, o pai é Promotor, tem um carro. Esfregou no chão o sapato novo, Eliná de chinelo de dedo, daqueles que o Chico Anísio fala. A Alice tem sapato mas não tem peitos, Os meus dá para balangar. Balançar. E usa renda na calça. Até essa criar peito eu já casei. (VALLE, p. 18, grifos da autora).

2 De acordo com o Dicionário Priberam, assédio sexual define-se por "conjunto de actos ou ditos com intenções sexuais, geralmente levado a cabo por alguém que se encontra em posição (hierárquica, social, econômica etc.) privilegiada” (ASSÉDIO..., 2008-2013). 
É interessante observar, neste trecho, que a rivalidade e o contraste construído entre Eliná e Alice não se dá apenas pelos atributos físicos de cada uma das meninas. O contraste se estabelece, também, pela diferença de renda entre as duas, dado denotado pela oposição entre os sapatos de Alice e o chinelo de Eliná, além da oposição entre os empregos dos pais das duas: vemos, ao longo do conto, que o pai de Eliná é jardineiro e vemos, neste trecho, que o pai de Alice é promotor. Outro dado interessante que pode ser lido neste trecho é o ciúme presente no pensamento de Eliná quando ela afirma que Alice é a aluna favorita da professora por sua condição social e a maneira que ela encontra de se valorizar pelo tamanho de seus seios: "A Alice tem sapato mas não tem peitos. Os meus dá pra balangar. Balançar".

Note-se, ainda, que a personagem Eliná se autocorrige a todo momento, refletindo sobre a linguagem e sabendo quando e onde usá-la de maneira coloquial ou não: "não diga copeia. Na escola eu não digo, só em casa. Se falo penteia me caçoam, pêntia o cabelo" (VALLE, p. 18, grifos da autora). O uso culto das palavras é um dos motivos pelos quais Eliná admira a professora e deseja sua atenção, como podemos ver no seguinte trecho:

Dona Lair diz passem o traço, todo mundo risca de vermelho, vira tabela. Quando é ponto ela diz sublinha, a gente passa o traço e aí é sublinha, jeitos de dizer. Eu sublinho, parece parente.

[...] Tranca o armário e traz a chave, Ricardina, o segundo período acaba com o giz. E não apague a lousa! gritou Dona Lair.

Ela tinha escrito É FAVOR NÃO APAGAR com letra de livro.

Bonito é favor não apagar.

É favor olhar que tenho peitos.

É favor saber que uso sutiã. (VALLE, p. 19, grifos da autora).

São o interesse e admiração de Eliná sente pela professora que fazem com que ela encare o contato que tem com a professora de maneira diferente ao modo como encara o assédio que sofre de seu pai: o passo que o pai assedia Eliná enquanto ela está deitada em sua cama para dormir, e de maneira agressiva, Dona Lair seduz a menina e faz com que ela sinta prazer nas carícias que nela faz:

Tirou-lhe o uniforme depressa, abriu o chuveirinho miniatura, disse ducha e esfregou com

Revista Crioula - $\mathbf{n}^{\circ} 24$ - Dissidências de Gênero e Sexualidade nas Literaturas de Língua Portuguesa 
uma buxa molinha, disse, esponja. Passou em lugares que têm só um nome, o Jovelino escreve no muro, Dona Lair teve hora que pareceu o Pai, ficou com medo igual, mais fria a mão dela do que a água [...]. E Dona Lair abriu, como um anjo-da-guarda, uma toalha macia como o tapete da sala e pegou Eliná no colo, comprida e arredia, largando de pé na cadeira diante do grande espelho, com vergonha daquele inteiro, nunca tinha se visto assim, partes juntas. E passou uma esponja de pelinhos em todos os Iugares, emprestou uma blusa desabotoada, como os botões do peito onde pôs a mão nervosa, rindo com mais dentes, engrossando os lábios, ficando bonita. O Pai fica feio, escuro, os olhos brilhantes. (VALLE, p. 22, grifos da autora).

Note-se, neste trecho, que Eliná associa os toques da professora aos do pai, percebendo que a situação se trata, na verdade, de um assédio. No entanto, podemos ver, na comparação da professora a um anjo da guarda quando esta estende a toalha, que Eliná não a vê nela a ameaça que vê no pai, como podemos ver em "rindo com mais dentes, engrossando os lábios, ficando bonita. O Pai fica feio, escuro, os olhos brilhantes". Segundo Simone de Beauvoir, é comum que moças aceitem o carinho de mulheres e que rejeitem o carinho de homens, preferindo ter experiências com mulheres mais velhas por medo da violação: "é em parte por medo da violência, da violação, que a adolescente dedica amiúde seu primeiro amor a uma amiga mais velha antes do que a um homem" (BEAUVOIR, 1976, p. 83-84).

No entanto, não são apenas os artifícios sedutores da professora que levam Eliná a encarar a relação entre elas como prazerosa. Eliná, que já vê na professora uma autoridade, sente prazer em submeter-se a ela, por isso declara, desde o início do conto que é "gostoso ser mandada": "Se a mais velha se presta à coisa, a mais jovem se entregará com alegria a carícias mais ardentes. É comumente o papel passivo que então desempenhará porque deseja ser dominada, protegida" (BEAUVOIR, 1967, p. 155).

É em busca de proteção e de conforto que Eliná aceita a oferta de D. Lair, combinado ao erotismo que sente no contato com a professora, que Eliná deseja aceitar a oferta da professora em deixar de ir à escola e morar com ela:

Dona Lair alisou como o Pai. Um pouco mais leve, falando:

— Você quer morar comigo? Trabalhar aqui?

Eliná sentiu que o medo diminuía.

- Eu quero.

— De arrumar, a limpeza grande Dona Assunta faz no sábado. Mais para companhia. Para os outros a gente diz que é arrumadeira. Alisou mais. 
Eliná perdeu o medo.

- Você vem, dorme aqui, tenho um quarto só para você, tem guarda-roupa, colchão-de-mola. Come aqui e ganha de tudo.

- Eu gosto.

— Você dorme com quem?

- Com a Durvalina.

- Aqui vai ter cama só para você. Seu pente, sua escova, toalha tudo. A gente vai viver sossegada. Só nós duas.

— Não tem mais ninguém?

— Não, eu moro sozinha.

- A casa inteira? Até a cozinha?

Tudo. Alisou com força, Eliná começou a achar bom.

— Só que tem uma coisa: você tem que sair da escola.

- Mas por que? Eu gosto da senhora...

— Eu sei, meu bem. Abraçou Eliná, a cabeça contra o macio de paina dos peitos dela. Eliná teve vertigem, gostoso abraçar.

— Eu quero aprender.

— Não vai dar, aquelas meninas não servem para você...

— Mas eu gosto até de problemas! Quero o diploma, a Mãe vai pôr na moldura.

— Eu dou um certificado, vale que nem diploma...

- Vale?

- Até mais. Só gente melhor estuda particular. Eu escrevo assim: Certifico que Eliná dos Santos de treze anos, filha de...

— Joaquim dos Santos e Adelina Justa dos Santos...

— Isso! Tem conhecimentos equivalentes à $4^{\mathrm{a}}$ série, obtidos em curso por mim ministrado, em complementação à terceira série do primeiro grau. Depois eu ponho no quadro, você pendura na parede.

Fechou a blusa de Eliná. (VALLE, p. 22-23, grifos nossos).

Note-se, nos trechos grifados, que os toques da professora em Eliná são enumerados de maneira gradativa e que a reação de Eliná, por sua vez, também muda gradativamente: de medo ela passa a sentir desejo.

É com base nesse desejo e no conforto que a professora lhe oferece por ser mais abastada em troca de sua "companhia" que Eliná decide revelar os assédios que sofre do pai à sua mãe para que 
esta aceite sua mudança:

— O Pai mexe com a gente. Toda noite. Ele levanta e mexe.

- O que?

- O Pai é sem-vergonha. Eu quero ir embora, Mãe. Deixa eu ficar na Dona Lair. (VALLE, p. 26).

O conflito dramático, desta maneira, se desenvolve abordando dois grandes contrastes: a situação de pobreza da família de Eliná se opõe a situação abastada de Dona Lair, e o assédio do pai se opõe ao assédio de Dona Lair, uma vez que a escolha que Eliná tem de fazer envolve ou continuar sofrendo o assédio do pai ou mudar para a casa da professora e sofrer o assédio dela. Um dos motivos que levam a menina a escolher a professora é o fato de ela morar em uma casa pobre e a professora ter uma vida abastada, possuindo vários objetos aos quais Eliná não tem acesso na casa de seus pais. É possível que o nome do conto venha do interesse de Eliná por esses objetos e pela vida abastada. Podemos ver esse interesse claramente no diálogo da protagonista com a mãe no qual ela fala sobre a casa de Dona Lair. Outra possibilidade, no entanto, é que o título do conto se refira a ela e a Dona Lair: Eliná se objetifica e se troca por boas condições e, já iniciada sexualmente, vê, também, Dona Lair, como objeto de desejo: "toda adolescente receia a penetração, o domínio masculino, experimenta em relação ao homem certa repulsa; em compensação, o corpo feminino é, para ela, como para o homem, um objeto de desejo" (BEAUVOIR, 1967, p. 146).

Percebe-se, dessa maneira, que a sexualidade de Eliná é construída por meio do assédio sofrido e os quais ela normaliza, considerando-os, de certa forma, naturais. No entanto, o desejo que Dona Lair desperta nela, ainda que se some à mudança de vida oferecida e faça com que ela ceda a proposta de Dona Lair, não é fruto apenas do assédio e da mudança oferecida: ele está presente desde a sala de aula, manifestado pela admiração à professora e pelos desejos de atenção e de ser escolhida pela professora. 


\section{Referências bibliográficas}

BEAUVOIR, Simone de. O segundo sexo: fatos e mitos. Tradução de Sérgio Milliet. São Paulo: Difusão Europeia do livro, 1970.

O segundo sexo: a experiência vivida. Tradução de Sérgio Milliet. São Paulo:

Difusão Europeia do livro, 1967.

REIMÃO, Sandra; Reagindo à censura: criatividade em tempos sombrios. O caso do concurso de contos da revista Status. Comunicação \& inovação. São Caetano do Sul, v. 9, n. 16, p. 1-6, jan.-jun./2008. Disponível em: https://seer.uscs. edu.br/index.php/revista_comunicacao_inovacao/article/view/685/531. Acesso em 24 out. 2019.

REZENDE, Vera Lúcia Guimarães. Da crônica jornalística ao conto: a transformação da escrita em Dinorath do Valle. 2019. 231 f. Tese (Doutorado em Letras) - Universidade Estadual Paulista Júlio de Mesquita Filho, São José do Rio Preto, 2003.

SILVA, Antonio Manoel dos Santos. Dinorath do Vale: literatura e experiência midiática. In: Os bárbaros submetidos. São Paulo: Unimar, 2006, p. 135-147.

VALLE, Dinorath do. Idade da Cobra Lascada. São Paulo: Editora Prelo, 1982 